\title{
As técnicas argumentativas nos discursos de parlamentares do PSDB sobre o Mensalão em sessões plenárias da Câmara dos Deputados
}

\author{
The argumentativetechniques in the PSDB parliamentarians' speeches \\ abouttheMensalão in plenarysessionsoftheChamberofDeputies
}

\author{
Elisabeth Linhares CATUNDA* \\ Universidade da Integração Internacional da Lusofonia Afro-Brasileira (UNILAB) \\ Léia Cruz MENEZES * \\ Universidade da Integração Internacional da Lusofonia Afro-Brasileira (UNILAB) \\ José Olavo da Silva GARANTIZADO JÚNIOR *** \\ Universidade da Integração Internacional da Lusofonia Afro-Brasileira (UNILAB)
}

\begin{abstract}
RESUMO:A presente pesquisa tem como objetivo analisar quais as técnicas argumentativas presentes nos discursos políticos dos deputados do PSDB, sobre o mensalão, em sessões plenárias da Câmara dos Deputados Federal. Para isso, nossa base teórica são os achados da Nova Retórica, de Perelman e Tyteca (1996), sobre as técnicas argumentativas, e o trabalho de Garantizado Júnior (2015), em seu modelo de análise e descrição do fenômeno argumentativo sob uma perspectiva textual e retórica, especialmente sobre os aspectos das técnicas argumentativas existentes no Componente Retórico da argumentação. O corpus foi constituído de nove discursos de parlamentares do PSDB sobre o julgamento do mensalão no Supremo Tribunal Federal (STF), no ano de 2013. Os resultados demonstram que as estratégias argumentativas são fenômenos sociodiscursivos presentes nos discursos dos parlamentares do PSDB, com o objetivo de defender a tese de que o mensalão existiu e que o julgamento no Supremo Tribunal Federal é legítimo.
\end{abstract}

Palavras-chave: Técnicas Argumentativas. Mensalão. Discurso do PSDB.

ABSTRACT: The present paper aims to analyze the argumentative techniques present in the political discourses of the PSDB deputies on the Mensalão payment in plenary sessions of the Federal Chamber of Deputies. For this, our theoretical basis will be the findings of the New Rhetoric, by Perelman and Tyteca (1996), on argumentative techniques, and the work of Garantizado Júnior (2015), in its model of analysis and description of the argumentative phenomenon from a textual perspective and rhetoric, especially on aspects of argumentative techniques in the Rhetoric Component of argumentation. The corpus was constituted by 9 speeches of parliamentarians of the PSDB on the judgment of the Mensalão in the Supreme Federal Court (STF) in 2013. The results show that the argumentative strategies are sociodiscursive phenomena present in the discourse of the parliamentarians of the PSDB, with the objective of Defend their thesis that the Mensalão existed and that the judgment in the Federal Supreme Court is legitimate.

Keywords: Argumentative Techniques. Mensalão. Speech by the PSDB.

Doutora em Linguística e professora adjunta do Instituto de Desenvolvimento Rural da UNILAB, Redenção - CE. bethcatunda@unilab.edu.br

Doutora em Linguística e professora adjunta do Instituto de Humanidades e Letras da UNILAB, Redenção - CE. leiamenezes@unilab.edu.br

Doutor em Linguística e professor adjunto do Instituto de Humanidades e Letras da UNILAB, Redenção -

CE. olavogarantizado@unilab.edu.br 


\section{Introdução}

No dia 02 de agosto de 2012, o ministro do Supremo Tribunal Federal (STF), Joaquim Barbosa, apresentava para a sociedade brasileira o relatório de acusação pela Procuradoria Geral da República sobre o caso que ficou conhecido como "Mensalão". Assim, iniciava-se um dos julgamentos mais importantes de toda a história brasileira, cujo objetivo era julgar, segundo constava o relatório, os envolvidos em um "esquema" de propina mensal para parlamentares integrantes de partidos políticos tradicionais da república brasileira, como o Partido Progressista (PP), Partido Liberal (PL e Prona se fundiram dando origem ao Partido Republicano-PR), Partido Trabalhista Brasileiro (PTB), Partido da Mobilização Democrática Brasileira (PMDB), além do Partido dos Trabalhadores (PT). Alguns parlamentares dessas agremiações políticas receberam dinheiro, pessoalmente ou por intermediários, para apoiar projetos do governo federal, por meio do esquema de lavagem, operacionalizado por Marcos Valério e seu grupo empresarial, junto com dirigentes do Banco Rural. Valério, que tinha contratos com o governo e era sócio nas agências DNA Propaganda e SMP\&B Comunicação, obteve empréstimos fraudulentos dos bancos Rural e BMG e teria ainda enviado, de forma ilícita, dinheiro para o exterior.

No dia 03 de agosto de 2012, Roberto Gurgel, procurador-geral da República, no segundo dia de julgamento, proferiu o discurso de acusação e enfatizou que havia provas da existência do Mensalão. Para o procurador, o ex-ministro da Casa Civil, José Dirceu, seria o líder do esquema, enquanto o empresário Marcos Valério seria o operador financeiro e, desse modo, o jurista solicitava a prisão de 36 réus do processo. Na última sessão do julgamento do mensalão, no dia 17 de dezembro de 2012, os ministros do STF decidiram cassar os mandatos dos três deputados condenados: João Paulo Cunha (PT-SP), Valdemar Costa Neto (PR-SP) e Pedro Henry (PP-MT). Os magistrados fizeram ainda algumas correções nas penas e, após mais de quatro meses, declararam encerrado o julgamento que marcou toda a história recente da política brasileira.

Nesses quatro meses de julgamento do processo mais emblemático para jurisprudência do Brasil, o clima nas casas legislativas era acirrado. O Partido dos Trabalhadores estava coagido, em uma situação de insegurança política, tendo de se 
defender das acusações de corrupção. Nesse contexto, a oposição era comandada pelo Partido da Social Democracia Brasileira (PSDB), que objetivava demonstrar o quão o governo petista não representava os anseios da população brasileira. Assim, a partir desse contexto de turbulência política e jurídica que o Brasil vivia, os discursos dos parlamentares do PSDB na Câmara dos Deputados são um objeto de estudo valioso para os analistas do tex to e do discurso.

Tomando os pronunciamentos dos parlamentares do PSDB nas sessões plenárias como um evento sociodiscursivo, sua repercussão na mídia digital e os textos deles resultantes como objetos de análise, neste trabalho, examinamos:

(i) o discurso argumentativo de que se valem os parlamentares do PSDB, que tentam banalizar a crise política brasileira, causada pelo julgamento do "esquema" do Mensalão;

(ii) as principais técnicas argumentativas presentes nos pronunciamentos dos parlamentares do PSDB e como são usadas para a defesa dos argumentos levantados pelos parlamentares.

Os procedimentos teórico-metodológicos adotados neste trabalho retomam, em perspectiva interdisciplinar, aos postulados de Perelman e Tyteca (1996), sobre as técnicas argumentativas, que influenciaram o desenvolvimento do Componente Retórico, desenvolvido por Garantizado Júnior (2015), sobre a argumentação numa perspectiva textual e retórica. Para fins de organização dos dados e dos resultados, optamos por seguir com os debates teórico e analítico conjuntamente, começando pelos aspectos teóricos sobre as estratégias argumentativas e finalizando com demonstração analítica delas em discursos dos parlamentares do PSDB.

Nesse sentido, nosso trabalho é relevante para os estudos da linguagem em geral, assim como para as áreas afins, porque analisamos o discurso dos parlamentares de um dos principais partidos de oposição na época do escândalo do mensalão, a fim de trazermos à baila os estudos provenientes da Nova Retórica. Além disso, ao analisarmos os discursos políticos dos parlamentares do PSDB em sessões plenárias da Câmara dos Deputados Federal, estamos promovendo uma interface entre o discurso político e as estratégias de persuasão usadas pelos seus Locutores no que tange à argumentação, 
entendendo que esses discursos são documentos importantes para as áreas de Linguística, História, Sociologia, Filosofia, Ciências Políticas e Direito.

\section{As técnicas argumentativas e o componente retórico da argumentação}

O estudo dos fenômenos argumentativos, em especial os que se pautavam pelos raciocínios dialéticos (retóricos), ficou praticamente esquecido durante muito tempo. Acerca disso, Fábio Ulhoa Coelho, no prefácio da edição brasileira do Tratado da Argumentação, já nos aponta esse esquecimento, quando nos diz que "vinte e três séculos se passaram enquanto a filosofia prestigia, do legado aristotélico, apenas o modo analítico de racionar. Ninguém manifesta preocupação em resgatar a ideia de dialética como um saber necessário" (PERELMAN; TYTECA, 1996, p. XIV). O retorno do pensamento com base nos raciocínios retóricos se deu a partir da segunda metade do século XX, quando os estudos relacionados à Dialética e a Retórica tomam um novo impulso.

Isso se deu por conta de uma ruptura com o pensamento cartesiano (baseado no pensamento de Descartes). Essa ruptura acabou originando o chamado Póscartesianismo, influenciando alguns autores, principalmente na Europa, a se dedicarem ao estudo da Argumentação e da Retórica, disciplinas que ficaram esquecidas durante séculos. Assim, Chaïm Perelmanem parceria com Lucie Olbrecht-Tyteca, com a publicação do Tratado de Argumentação: Nova Retórica, foram responsáveis pela retomada do pensamento aristotélico como basilar nos estudos sobre Argumentação.

Com Perelman e Tyteca (1996), os estudos sobre Argumentação e Retórica tomam um novo rumo. Consideramos que a publicação do "Tratado" representou uma ruptura com a maneira de se conceber a razão e o raciocínio do pensamento cartesiano proposto por Descartes. Em outras palavras, Perelman e Tyteca (1996) propõem uma "Nova Retórica", teoria da argumentação contrária ao posicionamento cartesiano, modelo teórico que predominava até então nos estudos da linguagem, viabilizando uma retórica baseada nas formas de se discutir e se chegar a um acordo sobre valores, sem 
abandonar o campo da razão, mas, ao mesmo tempo, transcendendo as categorias da lógica-formal.

A Nova Retórica tem uma íntima ligação com a retórica clássica, embora Perelman e Tyteca (1996) promovam algumas mudanças, o que justifica o adjetivo "Nova". De fato, essa nova abordagem retoma parte do pensamento clássico, mas promove alguns avanços. Consideramos que o modelo proposto está associado diretamente à arte do falar bem, ou mais que isso em alguns momentos, já que ela está voltada para a forma de falar e de conseguir um efeito esperado. Nessa nova realidade de lidar com a argumentação, a Nova Retórica dispensa o discurso falado informal e vai em busca de um discurso mais elaborado quanto às múltiplas possibilidades de aspectos lógicos, valorizando as razões, os convencimentos e, com certeza, motivando o estudo da persuasão. Assim, busca-se estudar todos os tipos de auditórios, não se restringindo a nenhum, podendo ser desde um auditório mais leigo até um mais especializado.

Um dos principais pontos da Nova Retórica é quanto à questão da adesão. Sabemos que Perelman e Tyteca (1996) usam o termo adesão, associando-o diretamente ao uso persuasivo do discurso e, dessa maneira, propõem uma relação entre adesão e ação. De fato, essa relação é oportuna e se justifica, porque a argumentação é vista sob a ótica de ser uma ação de natureza discursiva. Não podemos esquecer que o ato argumentativo em si já carrega consigo uma espécie de pré-disposição a determinada ação. Na verdade, defendem que querer persuadir um auditório significa reconhecer as capacidades e as qualidades de um ser com o qual a comunicação é possível e, em seguida, renunciar a dar-lhe ordens que exprimam uma simples relação de força, procurando, assim, sua adesão.

No capítulo da Nova Retórica denominado O acordo, Perelman e Tyteca (1996) se dedicam à averiguação do que seria aceito como ponto de partida dos raciocínios, assim, consideram diretamente as premissas da argumentação. Os acordos pertencentes ao real são determinados conforme uma realidade preexistente; os acordos pertencentes ao preferível não são conforme uma realidade. Para Perelman e Tyteca (1996), o conceito de auditório universal e a ideia do que seja real para essa concepção de auditório são conceitos historicamente delimitados. Para os autores, a noção seria uma espécie de imagem criada pelo Locutor a partir do que sabe seus semelhantes. 
Perelman e Tyteca (1996) empreendem estudo do modo argumentativo de discurso, tentando aproximar a "argumentação" e a técnicas da demonstração, em decorrência, principalmente, à ênfase concedida à argumentação que, de alguma maneira, volta-se para o auditório universal, como se o conceito fosse aplicado tal qual parece sugerir sua denominação. O conceito defendido pelos autores, para nós, possibilita que se pense em várias possibilidades de perspectivas que o Locutor pode atingir em interação com seu auditório.

O Tratado de Argumentação: a Nova Retórica, em sua terceira parte, é dedicado ao processo de compreensão de esquemas argumentativos, sendo três capítulos destinados à análise de esquemas de ligação (os argumentos quase-lógicos, os argumentos baseados na estrutura do real, os argumentos que visam a fundar a estrutura do real), um capítulo à análise de técnicas de dissociação e, por último, um capítulo que busca analisar os esquemas de argumentos com o objetivo de proporcionar a interação dos argumentos. Essa proposta influenciou diversificadas áreas do conhecimento que objetivam destacar as manifestações das técnicas argumentativas em variados objetos de análises textuais e discursivas.

Essa influência pode ser notada no trabalho de Garantizado Júnior (2015), que desenvolveu um modelo de argumentação no qual descreve os fenômenos argumentativos a partir de três planos: Plano Externo ao texto - Elementos Externos ao texto, constituído pelo contexto sócio-histórico (contexto amplo) e situação comunicativa e lugar de produção do texto (contexto específico), Plano Textual da argumentação (Componente Genérico e Componente Sequencial) e Plano Retórico da argumentação (Componente Retórico- técnicas argumentativas e projeções do éthos no discurso). No que se refere aos aspectos retóricos, percebemos uma forte influência do pensamento de Perelman e Tyteca (1996) para a constituição do que Garantizado Júnior (2015) denomina de Componente Retórico.

Para Garantizado Júnior (2015) ${ }^{1}$, o Componente Retórico da argumentação é constituído de dois importantes aspectos: a) das estratégias argumentativas capazes de

\footnotetext{
${ }^{1} \mathrm{Na}$ tese de doutoramento de Garantizado Júnior (2015), as técnicas argumentativas eram apenas um dos elementos constituintes do Componente Retórico da argumentação. Para ele, havia, dentro desse componente, as projeções do éthos e as técnicas argumentativas. Entretanto, ele defende que as duas categorias poderiam ser analisadas separadamente, sem prejuízo teórico e metodológico para a descrição do Componente Retórico, o que nos motivou a usar as definições dessa proposta neste trabalho, pois são,
} 
provar os argumentos do Locutor (PERELMAN; TYTECA, 1996) e b) das projeções do éthos, páthos e logos (AMOSSY, 2011). O que o pesquisador chama de Componente Retórico diz respeito às investidas do Locutor em tentar apresentar-se para o seu auditório a partir da construção de uma imagem positiva de si, além das técnicas de persuasão. Nos textos de cunho argumentativo, percebemos a construção de uma imagem, mesmo se esta for involuntária. Desse modo, o éthos, como já preconizava Aristóteles em sua Retórica, assim como o éthos defendido por Amossy (2011), ganha destaque na proposta de Garantizado Júnior (2015). Estudar a argumentação sem considerar essa importante "artimanha discursiva" para a construção da persuasão seria negligenciar o papel das técnicas argumentativas que o Locutor usa para chegar aos seus objetivos no ato argumentativo. Destacamos que, neste trabalho, nosso foco não será as técnicas argumentativas que o Locutor usa para projetar uma imagem de si no discurso, mas as técnicas argumentativas que ele usa para provar suas teses.

A retórica de Aristórteles e a Nova Retórica de Perelman e Tyteca (1996) inspiraram a proposta de Garantizado Júnior (2015) no que se refere à abordagem das técnicas argumentativas. Garantizado Júnior (2015) ressalta que "o Componente Retórico contará com a integração de conceitos da Retórica e Nova Retórica no que se refere ao acordo e ao estabelecimento do discurso frente aos tipos de argumento, ou seja, 'beberemos da fonte' aristotélica, assim como da de Perelman e Tyteca (1996)" (GARANTIZADO JÚNIOR, 2015, p. 177). Passemos, portanto, para a apresentação das técnicas argumentativas presentes nos discursos dos parlamentares do PSDB em sessões plenárias da Câmara dos Deputados Federal sobre o Mensalão.

\section{As técnicas argumentativas usadas pelos parlamentares do PSDB}

Ao nos debruçarmos sobre os pronunciamentos dos parlamentares do PSDB nas sessões plenárias da Câmara dos Deputados, observamos uma diversidade de estratégias argumentativas de que se valem esses Locutores com o intento de apontar a crise política brasileira a partir do julgamento do mensalão. Nos nove discursos dos Locutores do PSDB que constituem nosso corpus, mapeamos esquemas argumentativos

na verdade, as mesmas técnicas já apresentadas pela Nova Retórica, mas sistematizadas dentro de um modelo que considerava outros aspectos da argumentação. 
que se caracterizam por processo de ligação de noções (PERELMAN; TYTECA, 1996), a saber: argumentos quase-lógicos, argumentos baseados na estrutura do real e argumentos que fundam a estrutura do real.

Os argumentos quase-lógicos caracterizam-se por sua "aparência demonstrativa", ou seja, por terem sua força persuasiva advinda da proximidade que mantêm com os modelos de raciocínios formais, lógicos ou matemáticos. Nos dados analisados, há a ocorrência dos seguintes argumentos quase-lógicos: (1) argumentação pelo ridículo,(2) argumentação por definição,(3) argumentação regra de justiça, (4) argumentação pelo recurso às relações recíprocas,(5) argumentação pela regra de precedente, (6) argumentação pela comparação, (7) argumentação pelo sacrifício. Para fins de sistematização, observemos o quadro a seguir com os principais argumentos quase-lógicos presentes nos discursos analisados, os trechos dos discursos dos parlamentares e os comentários analíticos sobre as estratégias. Destacamos que, nos quadros subsequentes, os trechos em "Argumentos do Locutor" são excertos extraídos de cinco dos nove discursos que constituem nosso corpus - especificamente os discursos que enumeramos, apenas para nossa organização do corpus, de 01, 02, 04, 05 e 09 -, todos proferidos em sessões plenárias da Câmara dos Deputados Federal por parlamentares do PSDB. Esses discursos estão disponíveis no Portal da Câmara dos deputados e foram obtidos no sítio www.camara.gov.

Quadro 1- Os argumentos Quase-lógicos usados pelos parlamentares do PSDB

\begin{tabular}{|c|c|c|}
\hline \multicolumn{3}{|c|}{ ARGUMENTOS QUASE-LÓGICOS } \\
\hline $\begin{array}{c}\text { TÉCNICAS } \\
\text { ARGUMENTATIVAS }\end{array}$ & $\begin{array}{c}\text { ARGUMENTOS DO } \\
\text { LOCUTOR (TRECHOS) }\end{array}$ & COMENTÁRIOS ANALÍTICOS \\
\hline $\begin{array}{l}\text { Argumentação pelo ridículo. } \\
\text { Consiste em partir, com } \\
\text { ironia, de vestígios de uma } \\
\text { tese oposta à tese que se } \\
\text { quer defender para por em } \\
\text { evidência } \\
\text { incompatibilidades entre } \\
\text { ambas. }\end{array}$ & $\begin{array}{l}\text { “O que me preocupa é ver o PT } \\
\text { recriminando quando a lei é } \\
\text { feita. A legislação foi acertada, } \\
\text { e foi esta Casa que criou a lei. } \\
\text { O STF cumpriu essa lei. A } \\
\text { maioria do Pleno foi indicada } \\
\text { pelo próprio PT, pela } \\
\text { Presidenta Dilma ou pelo } \\
\text { Presidente Lula. Hoje, a grande } \\
\text { maioria do STF foi indicada } \\
\text { pelo Partido dos } \\
\text { Trabalhadores. Imagina-se que } \\
\text { o STF teria uma posição } \\
\text { diferente daquilo que foi } \\
\text { julgado?" (DISCURSO 4) }\end{array}$ & $\begin{array}{l}\text { Neste construto argumentativo, em } \\
\text { que se faz presente a ironia, o } \\
\text { Locutor faz referência ao fato de o } \\
\text { PT ter indicado os ministros do STF } \\
\text { e, no julgamento do mensalão, o } \\
\text { partido questionar a posição da corte } \\
\text { frente ao processo. Por este } \\
\text { argumento, tenta-se expor ao } \\
\text { ridículo o grupo de políticos do PT, } \\
\text { em especial o presidente da época, } \\
\text { Lula, responsável por indicar os } \\
\text { ministros. }\end{array}$ \\
\hline & "Chega de querer dizer que a & Neste discurso, o Locutor usa da \\
\hline
\end{tabular}




\begin{tabular}{|c|c|c|}
\hline & $\begin{array}{l}\text { impunidade vai continuar e que } \\
\text { quando alguém é punido é } \\
\text { porque existe uma elite contra } \\
\text { o PT, que a imprensa é contra o } \\
\text { PT, que o Supremo Tribunal é } \\
\text { contra o PT e que até o } \\
\text { Presidente do Supremo, } \\
\text { Ministro Joaquim Barbosa, é } \\
\text { contra o PT." (DISCURSO 9) } \\
\end{array}$ & $\begin{array}{l}\text { ironia para indicar que o PT possui } \\
\text { um argumento de que "há uma elite } \\
\text { contra" o partido. Isso se confirma } \\
\text { na tentativa de expor o PT como } \\
\text { vítima. }\end{array}$ \\
\hline $\begin{array}{l}\text { Argumentação por } \\
\text { definição. } \\
\text { Consiste na identificação de } \\
\text { diversos elementos que são } \\
\text { o objeto do discurso. }\end{array}$ & $\begin{array}{l}\text { "A vítima é a sociedade deste } \\
\text { País. Querem transformar o } \\
\text { crime que o político cometeu } \\
\text { em crime político. Foi o } \\
\text { político quem cometeu o } \\
\text { crime! Essa é a verdade." } \\
\text { (DISCURSO 9) }\end{array}$ & $\begin{array}{lcr}\text { Por meio de } & \text { uma } & \text { definição de } \\
\text { "vítima", o Locutor argumenta que a } \\
\text { população é } & \text { quem } & \text { está sendo } \\
\text { penalizada } & \text { pelos } & \text { problemas } \\
\text { construídos } & \text { pelos } & \text { políticos } \\
\text { brasileiros. } & & \end{array}$ \\
\hline $\begin{array}{l}\text { Argumentação pelo recurso } \\
\text { às relações recíprocas. } \\
\text { Consiste em aproximar, por } \\
\text { correspondência, situações } \\
\text { aparentemente distintas. }\end{array}$ & $\begin{array}{l}\text { "Quem legisla é o Congresso. } \\
\text { Se eu admitir que a Lei } \mathrm{n}^{\circ} \\
8.038 \text { não exauriu a matéria, } \\
\text { mas que poder ser } \\
\text { complementada ra pelo } \\
\text { regimento, eu teria uma ruptura } \\
\text { do princípio da isonomia. Para } \\
\text { mim, o quadro que me impede } \\
\text { de acompanhar a ilustradíssima } \\
\text { divergência é que a } \\
\text { competência para legislar sobre } \\
\text { processos é da União. O } \\
\text { Congresso atuou de maneira } \\
\text { completa." (DISCURSO 1) }\end{array}$ & $\begin{array}{l}\text { Neste momento de seu discurso, o } \\
\text { Locutor apresenta-se com relações } \\
\text { de simetria entre a Lei e a } \\
\text { efetividade dela. A alegação da } \\
\text { ruptura do princípio de isonomia } \\
\text { constituinte nela é o argumento que } \\
\text { consolida a tentativa de indicação do } \\
\text { uso das relações de reciprocidades } \\
\text { jurídicas entre os que tinham a } \\
\text { jurisprudência para legislar sobre os } \\
\text { embargos infringentes que estavam } \\
\text { sendo debatidos no STF. }\end{array}$ \\
\hline $\begin{array}{l}\text { Argumentação pela regra de } \\
\text { justiça. } \\
\text { Consiste em postular que } \\
\text { casos semelhantes devem ter } \\
\text { tratamento semelhante }\end{array}$ & 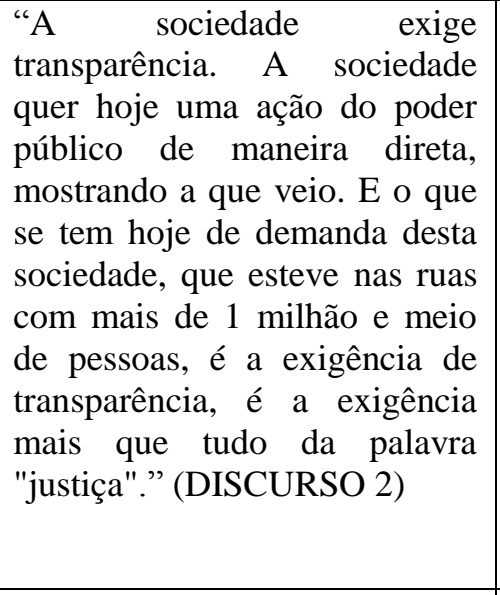 & $\begin{array}{l}\text { A partir de um argumento de que a } \\
\text { justiça que já fora feita no passado, } \\
\text { em outros casos de políticos, mesmo } \\
\text { que o momento fosse diferente, deve } \\
\text { ser tratado de maneira semelhante. } \\
\text { Por meio desse argumento, o } \\
\text { Locutor tenta defender a tese de que } \\
\text { o PT usava do argumento "contra a } \\
\text { corrupção", mas quando esse } \\
\text { argumento recai sobre o PT, não há } \\
\text { similaridades na condução das } \\
\text { interpretações dos embargos } \\
\text { infringentes no processo do } \\
\text { mensalão no STF. }\end{array}$ \\
\hline 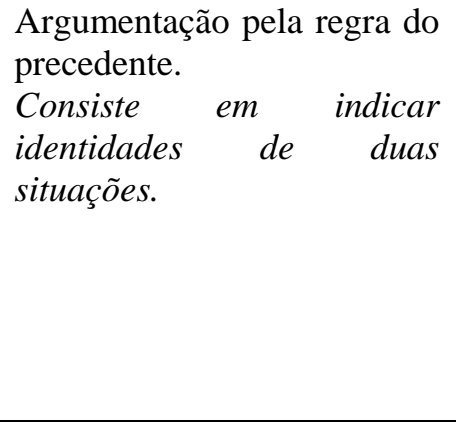 & $\begin{array}{l}\text { "A mais alta Corte do País, a } \\
\text { Suprema Corte do País, dentro } \\
\text { de um regime democrático, sob } \\
\text { o império da lei, que tem que } \\
\text { ser igual para todos, sem } \\
\text { privilégio para ninguém, } \\
\text { condenou por crime de } \\
\text { corrupção as pessoas que estão } \\
\text { hoje na cadeia." (DISCURSO } \\
\text { 5) }\end{array}$ & $\begin{array}{l}\text { Por meio do argumento de } \\
\text { codificação da jurisprudência dos } \\
\text { precedentes, em que um caso deve } \\
\text { ter o mesmo fechamento em outro } \\
\text { caso, o Locutor argumenta a } \\
\text { igualdade para todos e indica a } \\
\text { necessidade de que os crimes de } \\
\text { corrupção, que já foram usados em } \\
\text { outros processos no caso do } \\
\text { mensalão, também fossem na }\end{array}$ \\
\hline
\end{tabular}




\begin{tabular}{|c|c|c|}
\hline & & votação do julgamento do mensalão. \\
\hline $\begin{array}{l}\text { Argumentação } \\
\text { comparação. } \\
\text { Consiste em por em relação, } \\
\text { para fins de avaliação, dois } \\
\text { ou mais elementos a } \\
\text { apreciados } \\
\text { depreciados. }\end{array}$ & $\begin{array}{l}\text { "A diferença que nós estamos } \\
\text { vivendo hoje é que parece que } \\
\text { esse julgamento é um } \\
\text { julgamento de todos. Ora, o } \\
\text { Partido dos Trabalhadores não } \\
\text { pode desassociar este } \\
\text { momento. Têm que assumir } \\
\text { aqueles que cometeram erros, } \\
\text { assim como outros partidos } \\
\text { também podem cometer erro. } \\
\text { Mas daí a dizer que não } \\
\text { houve?!" (DISCURSO 4) }\end{array}$ & $\begin{array}{l}\text { O governo do PT, contra o qual se } \\
\text { projeta o discurso dos acusados do } \\
\text { mensalão, é comparado a governos } \\
\text { anteriores para evidenciar um } \\
\text { histórico de "atraso". Trata-se de um } \\
\text { argumento exposto para evidenciar a } \\
\text { histórica banalização da crise } \\
\text { política brasileira, com o objetivo de } \\
\text { indicar o PT como principal culpado } \\
\text { de todo o processo. A tese que se } \\
\text { estabelece é de que "se } \\
\text { compararmos os governos, } \\
\text { perceberemos que o PT não aceita } \\
\text { que cometeu erros". }\end{array}$ \\
\hline $\begin{array}{l}\text { Argumentação } \\
\text { sacrifício. } \\
\text { Consiste em, pelo } \\
\text { comparação, alegar um } \\
\text { sacrifício a se sujeitar para } \\
\text { a obtenção de determinado } \\
\text { resultado. }\end{array}$ & $\begin{array}{l}\text { "Quero deixar claro que nós do } \\
\text { PSDB não vamos torcer pelo } \\
\text { sacrifício, pelo sofrimento de } \\
\text { quem quer que seja, nem torcer } \\
\text { para que seja preso quem quer } \\
\text { que seja, mas nós vivemos } \\
\text { numa democracia. Há } 25 \text { anos } \\
\text { nós temos uma Constituição } \\
\text { em vigor, e não houve nenhum } \\
\text { momento de interrupção } \\
\text { democrática nessas últimas } 2 \\
\text { décadas e meia." (DISCURSO } \\
\text { 5) }\end{array}$ & $\begin{array}{l}\text { O Locutor indica o desgaste dos } \\
\text { membros do PSDB para que o } \\
\text { exercício da democracia fosse } \\
\text { concretizado. Alega-se um sacrifício } \\
\text { (de quem quer que seja) para a } \\
\text { obtenção de um resultado (a } \\
\text { constitucionalidade). Por meio desse } \\
\text { argumento, o Locutor tenta indicar } \\
\text { que o PSDB é um partido que se } \\
\text { orienta em prol da democracia. }\end{array}$ \\
\hline
\end{tabular}

Fonte: elaboração nossa

O quadro1 representa as diversas técnicas argumentativas de que se valem os parlamentares do PSDB para provarem a sua tese de que "o Mensalão existiu, o julgamento no SFT é legítimo e que deu direito ao contraditório aos acusados pelo MPF” (GARANTIZADO JÚNIOR, p. 273, 2015). Nesse contexto, as estratégias mencionadas estão expressas nos discursos políticos em sessões plenárias dos Locutores com o objetivo de provar a tese inicial abordada. Para isso, recorre-se a argumentos quase-lógicos, que podem revelar um engajamento do sujeito na linguagem através da persuasão. Esses tipos de argumentos "são aqueles preferíveis cuja conclusão não advém imperiosamente das premissas colocadas" (FIORIN, 2015, p. 115) e, desse modo, a conclusão é "provável, possível, plausível, mas não logicamente necessária” (FIORIN, 2015, p. 115).

Já os argumentos baseados na estrutura do real caracterizam-se por apresentarem "opiniões quanto ao que se considera real" (MENEZES, 2011, p. 122), ou seja, partem de uma base opinativa no mais das vezes fundada na ideia de senso 
comum. Nos dados, registramos a ocorrência dos seguintes argumentos enquadrados neste tipo: (1) argumentação pela ênfase nos fins e nos meios, (2) argumentação pelo recurso ao argumento de autoridade, (3) argumentação pelo recurso à interação entre orador e discurso e (4) argumentação pelo recurso à ligação simbólica. Assim como fizemos nos argumentos quase-lógicos, observemos o quadro abaixo, que contém as principais técnicas argumentativas que trazem esses argumentos como elemento central:

Quadro 2- Argumentos fundamentados na estrutura do real usados pelos parlamentares do PSDB

\begin{tabular}{|c|c|c|}
\hline \multicolumn{3}{|c|}{ ARGUMENTOS BASEADOS NA ESTRUTURA DO REAL } \\
\hline $\begin{array}{c}\text { TÉCNICAS } \\
\text { ARGUMENTATIVAS }\end{array}$ & $\begin{array}{c}\text { ARGUMENTOS DO } \\
\text { LOCUTOR (TRECHOS) }\end{array}$ & COMENTÁRIOS ANALÍTICOS \\
\hline $\begin{array}{l}\text { Argumentação pela ênfase } \\
\text { nos fins e nos meios. } \\
\text { Consiste em evidenciar, } \\
\text { através de relações } \\
\text { semânticas de fins e meios, } \\
\text { os caminhos (positivos ou } \\
\text { negativos) que se percorrem } \\
\text { para que se alcancem } \\
\text { alguns resultados. }\end{array}$ & $\begin{array}{l}\text { "Ora, se fosse crime político, } \\
\text { aí, nós estaríamos dizendo que } \\
\text { já não vivemos mais aquela } \\
\text { democracia, afinal, crime } \\
\text { político é quando um governo } \\
\text { encarcera alguém que é contra } \\
\text { aquele governo verdade visível } \\
\text { a todo mundo. Querem } \\
\text { mascarar a verdade, isso sim, } \\
\text { Sr. Presidente." (DISCURSO } \\
\text { 9). }\end{array}$ & $\begin{array}{l}\text { Entendemos meios e fins como } \\
\text { relações linguísticas tratadas na } \\
\text { argumentação para mostrar que } \\
\text { sucesso/fracasso, em dadas ações, } \\
\text { são resultado de meios ou fins } \\
\text { pretendidos por quem executa tais } \\
\text { ações (MENEZES, 2011). Neste } \\
\text { tocante, o Locutor se vale dessas } \\
\text { relações para mostrar que a verdade } \\
\text { mascarada é um meio de que se vale } \\
\text { o governo para chegar a um } \\
\text { resultado: dizer que não ocorreu o } \\
\text { mensalão no governo do PT. }\end{array}$ \\
\hline $\begin{array}{l}\text { Argumentação pelo recurso } \\
\text { ao argumento de autoridade. } \\
\text { Consiste em argumentar a } \\
\text { partir de estratégias que se } \\
\text { voltem para o discurso de } \\
\text { oradores de prestígio, ou } \\
\text { seja, o discurso de } \\
\text { autoridades. }\end{array}$ & $\begin{array}{l}\text { "Estou me referindo a } \\
\begin{array}{l}\text { declarações públicas de } \\
\text { Ministros. }\end{array} \\
\text { Declaração do Ministro } \\
\text { Ricardo Lewandowski: } \\
\text { "[A aceitação dos infringentes] } \\
\text { permite a derradeira } \\
\text { oportunidade de corrigir erro } \\
\text { de fato e de direito, sobretudo } \\
\text { porque encontra-se em jogo o } \\
\text { bem mais precioso da pessoa } \\
\text { depois da vida, que é seu } \\
\text { estado libertário." } \\
\text { (DISCURSO 1) }\end{array}$ & $\begin{array}{l}\text { O Locutor usa da autoridade do } \\
\text { Ministro do Supremo Federal, } \\
\text { Ricardo Lewandowiski, para } \\
\text { argumentar que o mensalão existiu e } \\
\text { que o julgamento dos criminosos é } \\
\text { legítimo, além de ser uma } \\
\text { oportunidade única para que a } \\
\text { sociedade acredite nas leis } \\
\text { brasileiras. }\end{array}$ \\
\hline $\begin{array}{l}\text { Argumentação pelo recurso } \\
\text { à interação entre orador e } \\
\text { discurso. } \\
\text { Consiste no estabelecimento } \\
\text { de um movimento interativo } \\
\text { entre orador e discurso, que } \\
\text { pode se estender ao } \\
\text { auditório, a fim de persuadi- } \\
\text { lo. }\end{array}$ & $\begin{array}{l}\text { "Alguém tem dúvida de que o } \\
\text { Ministro Lewandowski vai } \\
\text { defender a mudança do regime, } \\
\text { de fechado para semiaberto?" } \\
\text { (DISCURSO 1) }\end{array}$ & $\begin{array}{l}\text { Em sua fala, o parlamentar se } \\
\text { apropria de perguntas retóricas, } \\
\text { parte de seu discurso, e com elas } \\
\text { interage para estabelecer um } \\
\text { movimento dialogal com seu } \\
\text { auditório. Trata-se de perguntas com } \\
\text { tom moralista, que vão de encontro } \\
\text { ao discurso dos políticos presentes } \\
\text { na audiência pública, a quem o } \\
\text { Locutor se dirige diretamente. }\end{array}$ \\
\hline $\begin{array}{l}\text { Argumentação pelo r } \\
\text { à ligação simbólica. }\end{array}$ & $\begin{array}{l}\text { nbém posso levantar } \\
\text { re o Chefe de Estado }\end{array}$ & $\begin{array}{l}\text { A ideia de que Lula não seria mais o } \\
\text { símbolo da ética e da moral no país é }\end{array}$ \\
\hline
\end{tabular}




\begin{tabular}{|c|c|c|}
\hline $\begin{array}{l}\text { Consiste em evidenciar o } \\
\text { poder simbólico de um } \\
\text { objeto ou de uma causa que } \\
\text { se liga a um fim } \\
\text { argumentativo. }\end{array}$ & $\begin{array}{l}\text { no momento do mensalão, que } \\
\text { era o Presidente Lula. Qual é a } \\
\text { diferença? Qual é o medo de } \\
\text { fazer esse debate? Não } \\
\text { podemos ter medo desse } \\
\text { debate. Nenhum! Nenhum!" } \\
\text { (DISCURSO 4) }\end{array}$ & $\begin{array}{l}\text { posta em prática, como forma de } \\
\text { ligação desconstrução simbólica da } \\
\text { imagem do presidente a de uma } \\
\text { heroína. }\end{array}$ \\
\hline $\begin{array}{l}\text { Argumentação pelo recurso. } \\
\text { tu torque (você também). } \\
\text { Consiste em desqualificar o } \\
\text { argumento do outro. }\end{array}$ & $\begin{array}{l}\text { "Não é preciso tripudiar em } \\
\text { cima daqueles que já estão } \\
\text { presos, mas, acima de tudo, nós } \\
\text { não vamos aceitar que venham } \\
\text { a esta tribuna dizer que nós não } \\
\text { sabemos nada disso." } \\
\text { (DISCURSO 4) }\end{array}$ & $\begin{array}{l}\text { O Locutor usa o argumento de que } \\
\text { "não tripudiar" os cidadãos presos } \\
\text { (fazendo referência aos acusados } \\
\text { pelo STF que estavam em regime } \\
\text { fechado no momento do } \\
\text { julgamento), para desqualificar o } \\
\text { discurso petista de que "o } \\
\text { julgamento é injusto e não teve } \\
\text { direito ao contraditório". } \\
\text { (GARANTIZADO JÚNIOR, p. } \\
\text { 273, 2015) }\end{array}$ \\
\hline $\begin{array}{l}\text { Argumentação pelo recurso } \\
\text { do Argumentum ad } \\
\text { ignorantiam (apela para a } \\
\text { ignorância). } \\
\text { Consiste na tentativa } \\
\text { indicar que a naro } \\
\text { comprovação de um ponto } \\
\text { de vista implica que seu } \\
\text { contraditório } \\
\text { verdadeiro. }\end{array}$ & $\begin{array}{l}\text { "Nós não podemos acusar em } \\
\text { vão. } \\
\text { Eu sei que já tentaram trazer } \\
\text { aqui à baila o debate sobre } \\
\text { Minas Gerais, sobre outros } \\
\text { assuntos. O PSDB está pronto } \\
\text { para debater isso! Pronto! Eu } \\
\text { quero dizer aqui que, se têm } \\
\text { alguma dúvida - eu não tenho } \\
\text { nenhuma - sobre o nosso } \\
\text { partido." (DISCURSO 4) }\end{array}$ & $\begin{array}{l}\text { O Locutor, referindo-se às acusações } \\
\text { feitas pelo PT de que já existiu o } \\
\text { mensalão mineiro no governo do } \\
\text { PSDB naquele estado, usa da técnica } \\
\text { de que, como o STF havia se } \\
\text { manifestado de que o mensalão } \\
\text { mineiro não existiu e que não há } \\
\text { provas concretas, o argumento } \\
\text { "acusar em vão" é prova de que os } \\
\text { parlamentares do PT não podem } \\
\text { trazer à baila essa discussão e, sim, } \\
\text { centrá-la no julgamento em vigor. }\end{array}$ \\
\hline
\end{tabular}

Fonte: elaboração nossa

A partir do quadro 2, percebemos que os argumentos fundamentados na estrutura do real foram usados de forma muito produtiva pelos parlamentares do PSDB, principalmente, pelo Locutor 4. Como se sabe, esses argumentos são os que se baseiam "em relações que nosso sistema de significados considera no mundo do objetivo: casualidade, sucessão, coexistência e hierarquização" (PERELMAN; TYTECA, 1996, p. 297). O uso desse tipo de argumento pelos parlamentares do PSDB se justifica pelo fato desses sujeitos terem como objetivo principal a demonstração real de que o mensalão existiu e que, principalmente, o julgamento do caso no STF estava sendo legítimo. Especificamente, os parlamentares usaram desse artifício para demonstrarem que o julgamento tinha legalidade constitucional.

Por sua vez, os argumentos que fundam a estrutura do real caracterizam-se "pela presença de argumentos que recorrem a caso particular", recorrendo a dois tipos básicos de fundamentos, pelo caso particular e por analogia (MENEZES, 2011, p. 124). 
Nos dados, registramos ocorrência de: (1) argumentação pelo recurso ao exemplo, (2) argumentação por ilustração, (3) argumentação pelo recurso ao Ser perfeito como modelo e (4) argumentação pelo recurso à metáfora. Isso pode ser percebido no quadro abaixo:

Quadro 3- Argumentos que fundamentam a estrutura do real usados pelos parlamentares do PSDB

\begin{tabular}{|c|c|c|}
\hline \multicolumn{3}{|c|}{ ARGUMENTOS QUE FUNDAM A ESTRUTURA DO REAL } \\
\hline $\begin{array}{c}\text { TÉCNICAS } \\
\text { ARGUMENTATIVAS }\end{array}$ & $\begin{array}{l}\text { ARGUMENTOS DO } \\
\text { LOCUTOR (TRECHOS) }\end{array}$ & COMENTÁRIOS ANALÍTICOS \\
\hline $\begin{array}{l}\text { Argumentação pelo recurso } \\
\text { ao exemplo. } \\
\text { Consiste em recorrer a } \\
\text { exemplos para fundamentar } \\
\text { afirmações, regras elou } \\
\text { generalizações. }\end{array}$ & $\begin{array}{l}\text { "Nós estamos agora correndo o } \\
\text { risco efetivo de ver, na quarta- } \\
\text { feira, esse ambiente ser } \\
\text { sepultado, essa barragem que o } \\
\text { Supremo Tribunal Federal } \\
\text { construiu ser rompida. } \\
\text { Eu procurei como exemplo o } \\
\text { voto mais elucidativo." } \\
\text { DISCURSO 1) }\end{array}$ & $\begin{array}{l}\text { O Locutor usa a técnica de } \\
\text { demonstrar o exemplo do voto de } \\
\text { um dos ministros do SFT para } \\
\text { embasar a sua tese de que "o } \\
\text { mensalão existiu". }\end{array}$ \\
\hline $\begin{array}{l}\text { Argumentação por } \\
\text { ilustração. } \\
\text { Consiste em reforçar uma } \\
\text { tese tida como aceita por } \\
\text { meio de abonamento. }\end{array}$ & $\begin{array}{l}\text { "Não pode o Supremo se } \\
\text { curvar às pressões, sim, de } \\
\text { quem quer que seja, mas } \\
\text { também nám não pode } \\
\text { simplesmente, ignorando o } \\
\text { sentimento de frustração da } \\
\text { sociedade, estabelecer uma } \\
\text { decisão que frustre os jovens, } \\
\text { que hoje estão muito atentos ao } \\
\text { que está acontecendo no } \\
\text { Supremo Tribunal Federal e } \\
\text { que querem um país, como } \\
\text { sociedade, justo, e que se } \\
\text { estabeleça justiça nesse } \\
\text { processo." (DISCURSO 2) }\end{array}$ & $\begin{array}{l}\text { O Locutor usa a estratégia de indicar } \\
\text { situações ilustrativas que, caso o } \\
\text { STF não tomasse a medida pela } \\
\text { continuidade do julgamento dos } \\
\text { acusados do mensalão, a sociedade } \\
\text { ficaria frustrada com os detentores } \\
\text { das leis federais. }\end{array}$ \\
\hline $\begin{array}{l}\text { Argumentação pelo recurso } \\
\text { ao Ser perfeito como } \\
\text { modelo. } \\
\text { Consiste em recorrer a um } \\
\text { modelo como exemplo que } \\
\text { não possibilite contestação } \\
\text { de sua perfeição. }\end{array}$ & $\begin{array}{l}\text { "Alguns diziam, lá no passado: } \\
\text { "Mexeu com Lula, mexeu } \\
\text { comigo". Ora, não temos } \\
\text { nenhum problema. Eu acho que } \\
\text { as reservas morais têm que } \\
\text { ficar reservadas, mas os temas } \\
\text { que geraram escândalos, que } \\
\text { geraram denúncias, que } \\
\text { geraram ações e processos têm } \\
\text { o fórum para serem julgados. } \\
\text { Nesse fórum, já foram } \\
\text { julgados, já foram } \\
\text { sentenciados, inclusive já } \\
\text { ocorreu o final, que é a prisão." } \\
\text { (DISCURSO 4) }\end{array}$ & $\begin{array}{l}\text { Na medida em que, simbolicamente, } \\
\text { trata da ideia da personagem "anti- } \\
\text { herói" para Lula, o Locutor } \\
\text { argumenta em direção ao } \\
\text { questionamento do conceito de um } \\
\text { Ser perfeito, quase sempre, } \\
\text { empregado ao ex-presidente Lula } \\
\text { pelos seus colegas de partido. Por } \\
\text { meio desse argumento, o } \\
\text { parlamentar do PSDB indica a falta } \\
\text { de ética petista na condução dos } \\
\text { sujeitos que estavam sendo julgados } \\
\text { no julgamento do STF. }\end{array}$ \\
\hline $\begin{array}{l}\text { Argumentação pelo recurso } \\
\text { à metáfora. }\end{array}$ & $\begin{array}{l}\text { "Vamos respeitar o País } \mathrm{e} \\
\text { todos aqueles que querem um }\end{array}$ & 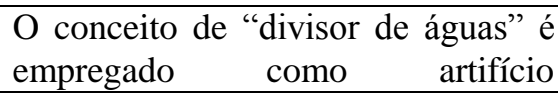 \\
\hline
\end{tabular}


Consiste em estabelecer uma analogia figurada, no plano da conotação, para ilustrar algum ponto que se deseja evidenciar na tese defendida.

\begin{tabular}{l|l} 
País melhor. O mensalão será & argumentativo para indicar que o \\
um divisor de água, não tenho & julgamento será um ponto de \\
dúvidas disso. Tomara que seja & $\begin{array}{l}\text { mudança para a democracia e para a } \\
\text { para um Brasil melhor!” } \\
\text { política brasileira. } \\
\text { (DISCURSO 4) }\end{array}$
\end{tabular}

Fonte: elaboração nossa.

As estratégias mencionadas acima, no quadro 3, são as que os argumentos fundamentam a estrutura do real, logo "são vistas como conformes à maneira como se estruturam a realidade, mas que são consideradas modos de organização da realidade" (FIORIN, 2015, p. 185) e essas estão expressas no pronunciamento em análise na medida em que são apropriadas pelo Locutor no discurso que a tese de que "mensalão é um ato ilegítimo" e que o PT sustentava este esquema, naquela época. Revelam, por assim dizer, um engajamento do sujeito na linguagem, através da persuasão, com o objetivo maior de problematizar o governo petista como "aquilo que deveria ter sido e não foi”, dados os grandes escândalos provenientes do Mensalão.

De maneira geral, todas essas estratégias, no fundamento do discurso dos parlamentares, tinham o foco de defesa do julgamento que, naquela época, estava colocando o governo do presidente Lula sob suspeitas, principalmente, por muitos membros da cúpula administrativa estarem envolvidos. Nesse sentido, a manutenção pelo debate dessas questões, a partir do julgamento, eram as principais ações dos parlamentares do PSDB para indicarem as imprecisões governamentais do PT no comando do país.

\section{Considerações finais}

O arcabouço teórico das técnicas argumentativas da Nova Retórica, de Perelman e Tyteca (1996), um dos elementos que constitui o Componente Retórico da proposta de análise e descrição da argumentação numa perspectiva textual e retórica, a partir da proposta de Garantizado Júnior (2015), serviram sobremaneira para analisarmos os discursos políticos dos parlamentares do PSDB em sessões plenárias sobre o Mensalão.

Destacamos que os resultados das análises apontam, em relação às categorias elencadas, que as técnicas argumentativas usadas pelos parlamentares do 
PSDB em sessões plenárias, sobre a temática do mensalão, tiveram como objetivo indicar o argumento de que o julgamento do mensalão era fundamental para a sociedade brasileira e, principalmente, legítimo. Na mesma direção, podemos afirmar que as relações entre a proposta da Nova Retórica e a proposta de análise da argumentação sob uma perspectiva textual e retórica dialogam nas mesmas categorias e fundamentos de análise, o que nos proporcionaram uma investigação das principais estratégias usadas nos 9 discursos dos parlamentares do PSDB que constituíram o corpus desta pesquisa.

Finalizamos, desse modo, relevando a importância de análises sobre o discurso político para a sociedade atual, principalmente, quando essas manifestações linguísticas retratam questões de corrupção que, de alguma maneira, envolvem toda a população. Reconhecemos o papel fundamental do pesquisador em Ciências Sociais, em especial, o pesquisador que se debruça em estudar a argumentação, pois este tem a árdua função de oferecer à sociedade possíveis respostas a muitos dos seus questionamentos em torno das formas sociais de interação, pelas quais se constroem os principais argumentos que serão usados, repetidos e consolidados pela sociedade. Por último, é importante que outros trabalhos possam fazer o confronto entre essas abordagens discursivas, demonstrando as particularidades que o Locutor do PT possui em suas estratégias, assim como as particularidades do Locutor do PSDB.

\section{REFERÊNCIAS}

AMOSSY, Ruth. Imagens de si no discurso: a construção do éthos. São Paulo: Editora Contexto, 2011.

FIORIN, José Luiz. Argumentação. 1. Ed. 1ª Reimpressão. São Paulo: Contexto, 2015.

MENEZES, Léia Cruz. Expressões linguísticas modalizadoras deônticas em função argumentativa: um exercício de análise retórico funcional. Tese de Doutorado. Programa de Pós-Graduação em Linguística da Universidade Federal do Ceará: Fortaleza, 2011.

PERELMAN, Chaïm; OLBRECHTS-TYTECA, Lucie. Tratado da argumentação: a nova retórica. Trad. Maria Ermantina de Almeida Prado Galvão. São Paulo: Martins Fontes, 1996.

GARANTIZADO JÚNIOR, José Olavo da Silva. Estudo da argumentação sob uma perspectiva textual e retórica. Tese (Doutorado) - Universidade Federal do Ceará, Centro de Humanidades, Departamento de Letras Vernáculas, Programa de PósGraduação em Linguística, Fortaleza, 2015. 